\title{
Cardiorespiratory response to feeding in newborn infants
}

\author{
VICTOR Y. H. YU \\ From the Department of Paediatrics, John Radcliffe Hospital, Oxford
}

\begin{abstract}
Yu, V. Y. H. (1976). Archives of Disease in Childhood, 51, 305. Cardiorespiratory response to feeding in newborn infants. Milk feeds were given through indwelling nasogastric tubes to 14 infants with respiratory distress. Similar cardiorespiratory disturbances were observed when the infants were fed $(5 \mathrm{ml} / \mathrm{kg}$ per feed) human milk, cow's milk, or distilled water. $\mathrm{PaO}_{2}$ fell after a feed but recovered to the prefeed value at 30 minutes, at which time $\mathrm{PaCO}_{2}$ had fallen and the respiratory rate had increased. No changes in $p \mathrm{H}$, heart rate, or blood pressure were observed. Portal sinus pressures rose after feeding in association with an increase in central venous pressure. In contrast, when the ill infants were fed human milk at a volume of $2.5 \mathrm{ml} / \mathrm{kg}$ per feed no consistent changes in any of the measurements were found.

These studies suggested that the cardiorespiratory effects were related to volume displacement resulting from feeds being introduced into the stomach. The relation of the increase in central venous pressure and the magnitude and direction of shunting in infants with the respiratory distress syndrome is uncertain. Adverse effects may be avoided by giving smaller, and therefore even more frequent, feeds.
\end{abstract}

In a preliminary study on infants suffering from respiratory distress (Wilkinson and $\mathrm{Yu}, 1974$ ) a transient fall in arterial oxygen tension was observed after nasogastric tube feeding. This confirmed the frequent observation of some degree of cyanosis after feeds in ill or immature infants. In the present study the influence of different types and volumes of feed on the cardiorespiratory responses to feeding is described. Feeds of human and cow's milk were compared with those of distilled water. The latter were unlikely to have any metabolic effect and thus would make it possible to determine the effect of volume displacement by feed alone. The previous study suggested a direct relation between the volume of feed per unit birthweight and the degree of hypoxaemia after feeding. This study also reports the effects on cardiorespiratory function of giving fecds in half the volume normally used in our nursery.

\section{Materials and methods}

Fourteen ill newborn infants and 7 control infants were studied. The ill infants were suffering from the respiratory distress syndrome (RDS) the presumptive

Received 31 July 1975 cause of which was hyaline membrane disease. The 7 control infants had had umbilical catheterization within an hour of birth because of low birthweight or early gestation and initial respiratory distress. However, the symptoms and signs subsided within the first $\mathbf{1 2}$ hours and the studies were performed just before removal of the catheter. These infants were considered to be healthy at the time of study as they had no abnormal findings on physical examination, had normal arterial $p \mathrm{H}$ and blood gases, and the subsequent course also proved to be uneventful. Table I gives the clinical data. 7 ill infants receiving pooled human breast milk were assigned to group I, and 7 ill infants on half-cream Cow and Gate were assigned to group II. 7 healthy control infants were assigned to group III. No significant differences were present with regard to birthweight or gestational age in these three groups. The ambient oxygen concentration at the time of study in the first two groups and the postnatal age when studied in all three groups were also comparable. The healthy control infants were nursed in room air at the time of study.

As the studies were carried out on infants in the first day of life (age range 5-24 hours), all were receiving feeds at a volume calculated to provide $60 \mathrm{ml} / \mathrm{kg}$ per day according to the high-volume regimen in use in the special care nursery. Furthermore, all were being fed intermittently at 2-hourly intervals and therefore each received a standard volume of $5 \mathrm{ml} / \mathrm{kg}$ per feed. Two 
TABLE I

Clinical data of infants studied (mean $\pm S E M$ )

\begin{tabular}{|c|c|c|c|c|c|c|}
\hline Infants & No. & $\begin{array}{c}\text { Birthweight } \\
\text { (g) }\end{array}$ & $\begin{array}{l}\text { Gestation } \\
(\mathbf{w})\end{array}$ & $\begin{array}{c}\text { Ambient } \\
\text { oxygen } \\
(\%)\end{array}$ & $\begin{array}{l}\text { Postnatal } \\
\text { age (h) }\end{array}$ & $\begin{array}{l}\text { Duration } \\
\text { of feed } \\
\text { (min) }\end{array}$ \\
\hline $\begin{array}{l}\text { Group I } \\
\text { (infants with RDS) } \\
\text { Group II } \\
\text { (infants with RDS) } \\
\text { Group III } \\
\text { (healthy infants) }\end{array}$ & $\begin{array}{l}7 \\
7 \\
7\end{array}$ & $\begin{array}{l}2664 \pm 310 \\
2391 \pm 173 \\
2444 \pm 193\end{array}$ & $\begin{array}{l}35 \pm 1 \cdot 3 \\
36 \pm 0 \cdot 7 \\
37 \pm 0 \cdot 5\end{array}$ & $\begin{array}{l}38 \pm 3 \cdot 3 \\
37 \pm 4 \cdot 0 \\
21 \text { (room air) }\end{array}$ & $\begin{array}{l}A=14 \pm 1 \cdot 9 \\
B=14 \pm 1 \cdot 9 \\
C=12 \pm 2 \cdot 2 \\
D=11 \pm 1 \cdot 8 \\
\star 13 \pm 1 \cdot 8\end{array}$ & $\begin{array}{l}A=6 \pm 1 \cdot 8 \\
B=5 \pm 1 \cdot 1 \\
C=5 \pm 1 \cdot 7 \\
D=5 \pm 1 \cdot 5 \\
\star 5 \pm 0 \cdot 7\end{array}$ \\
\hline
\end{tabular}

A, Human milk ( $5 \mathrm{ml} / \mathrm{kg}$ per feed).

B, Human milk $(2.5 \mathrm{ml} / \mathrm{kg}$ per feed).

C, Half-cream Cow and Gate $(5 \mathrm{ml} / \mathrm{kg}$ per feed).

$\mathrm{D}$, Distilled water $(5 \mathrm{ml} / \mathrm{kg}$ per feed).

$\star$ Human milk $(5 \mathrm{ml} / \mathrm{kg}$ per feed).

feeding studies were carried out consecutively in each of the ill infants at an interval of 2 hours. Infants in group I were given feeds of pooled human breast milk at a volume of $5 \mathrm{ml} / \mathrm{kg}$ per feed (study A) as well as $2.5 \mathrm{ml} / \mathrm{kg}$ per feed (study B). The smaller volume was half that of the standard feed and was therefore equivalent to the same high-volume regimen given at a more frequent interval of one hour. Infants in group II were given feeds of half-cream Cow and Gate at a volume of $5 \mathrm{ml} / \mathrm{kg}$ per feed (study C) and distilled water in an identical volume (study D). The order of the two feeds was alternated in each group.

Full details of the procedure for tube feeding and the methods of monitoring arterial blood pressure, heart rate, respiratory rate, arterial $p \mathrm{H}$, and blood-gas tensions were published in a previous article (Wilkinson and $\mathrm{Yu}$, 1974). Tube feeding was given via an indwelling nasogastric tube by the gravity method with infants lying supine and in a quiet or sleeping state before the observations were started. The infants were nursed naked, lying supine and horizontally in incubators. A size $5 \mathrm{~F}$ polyvinyl feeding tube was passed through the nose into the stomach and the infant was then allowed to settle to a resting quiet state before observations were started. Milk was allowed to run in by gravity from an open syringe outside the incubator about $30 \mathrm{~cm}$ above the infant. The mean duration of time for the feed to run in was 5 minutes (Table I). Abdominal aortic blood pressure was measured via an indwelling umbilical arterial catheter. Respiratory rate was counted from a Magnetometer (Lawlite, Sevenoaks, England) tracing. A 3-way tap was connected to the umbilical arterial catheter and placed outside the incubator, so that the infant and his environment were not disturbed during blood sampling. $0.5 \mathrm{ml}$ of arterial blood was drawn immediately before the feed and 15 and 30 minutes later for measurement of $p H$, oxygen, and carbon dioxide tensions (IL313, Instrumentation Laboratories, London).

A venous catheter was introduced through the ductus venosus into the inferior vena cava and positioned successfully in 9 infants as confirmed by $x$-ray pressure trace. In 12 infants it was not possible to introduce the catheter beyond the ductus venosus and the catheter tip was left in the portal sinus where the pressure was measured. The zero preference point for the pressure transducer (Bell and Howell, tube 4-327, Basingstoke, England) was set at the midaxillary line and recordings were made on a polygraph (type M19 recorder, Devices Ltd., London, England).

\section{Results}

Differences between the prefeed and postfeed values were evaluated by the paired t-test. The effects of feeding ill infants with human milk $(5 \mathrm{ml} / \mathrm{kg}$ per feed) are summarized in Table II. Feeding did not affect $p \mathrm{H} . \quad \mathrm{PaCO}_{2}$ remained unchanged except at the end of the 30-minute study period, when it had fallen (compared with prefeed levels, $\mathrm{P}<0 \cdot 02$ ). Mean $\mathrm{PaO}_{2}$ had fallen $9 \mathrm{mmHg}$ 15 minutes from the start of the feed but returned by 30 minutes to nearly the prefeed value. The

\section{TABLE II}

Cardiorespiratory effects of feeding with human milk (5 ml/kg per feed) infants with respiratory distress (mean $\pm S E M)$

\begin{tabular}{|c|c|c|c|}
\hline & Before feed & $\begin{array}{l}15 \mathrm{~min} \text { from } \\
\text { start of feed }\end{array}$ & $\begin{array}{l}30 \mathrm{~min} \text { from } \\
\text { start of feed }\end{array}$ \\
\hline $\begin{array}{l}\mathrm{pH} \\
\mathrm{PaCO}_{2} \text { (mmHg) } \\
\mathrm{PaO}_{2} \text { (mmHg) } \\
\text { Respiratory rate } \\
\text { (min) } \\
\text { Heart rate } \\
\text { (min) } \\
\text { Blood pressure } \\
\text { (mmHg) } \\
\text { Mean } \\
\text { Systolic } \\
\text { Diastolic } \\
\text { Pulse pressure }\end{array}$ & $\begin{array}{c}7 \cdot 33 \pm 0 \cdot 02 \\
31 \pm 2 \cdot 4 \\
74 \pm 4 \cdot 3 \\
89 \pm 4 \cdot 2 \\
138 \pm 2 \cdot 1 \\
\\
48 \pm 1 \cdot 8 \\
57 \pm 2 \cdot 0 \\
40 \pm 1 \cdot 4 \\
17 \pm 1 \cdot 0\end{array}$ & $\begin{array}{c}7 \cdot 33 \pm 0 \cdot 02 \\
32 \pm 2 \cdot 4 \\
65 \pm 1 \cdot 8 \star \\
93 \pm 4 \cdot 7 \\
140 \pm 2 \cdot 7 \\
\\
47 \pm 1 \cdot 7 \\
55 \pm 2 \cdot 2 \\
39 \pm 1 \cdot 6 \\
16 \pm 1 \cdot 0\end{array}$ & $\begin{array}{c}7 \cdot 33 \pm 0 \cdot 02 \\
27 \pm 2 \cdot 3^{\star} \\
72 \pm 2 \cdot 0 \\
95 \pm 3 \cdot 3 t \\
141 \pm 3 \cdot 3\end{array}$ \\
\hline
\end{tabular}

Compared with prefeed levels: ${ }^{\star} \mathrm{P}<0.02 ; \dagger<0.001$ (paired t-test). 
difference between the 15-minute and the prefeed value is significant $(P<0.02)$. Respiratory rate was increased at 30 minutes from the start of feed $(P<0.001)$. No consistent changes in heart rate or blood pressure were observed.

Results of feeding ill infants with half-cream Cow and Gate $(5 \mathrm{ml} / \mathrm{kg}$ per feed) were similar to feeding with human milk in identical volume (Table III). There was a significant drop in

\section{TABLE III}

Cardiorespiratory effects of feeding with half-cream Cow and Gate (5 ml/kg per feed) infants with respiratory distress (mean $₫ S E M$ )

\begin{tabular}{|c|c|c|c|}
\hline & Before feed & $\begin{array}{l}15 \mathrm{~min} \text { from } \\
\text { start of feed }\end{array}$ & $\begin{array}{l}30 \mathrm{~min} \text { from } \\
\text { start of feed }\end{array}$ \\
\hline $\begin{array}{l}\mathrm{pH} \\
\mathrm{PaCO}_{2} \text { (mmHg) } \\
\mathrm{PaO}_{2} \text { (mmHg) } \\
\text { Respiratory rate } \\
\quad \text { (min) } \\
\text { Heart rate } \\
\text { (/min) } \\
\text { Blood pressure } \\
\text { (mmHg) } \\
\text { Mean } \\
\text { Syst Jlic } \\
\text { Diastolic } \\
\text { Pulse pressure }\end{array}$ & $\begin{array}{c}7 \cdot 32 \pm 0 \cdot 03 \\
33 \pm 2 \cdot 8 \\
83 \pm 3 \cdot 1 \\
88 \pm 7 \cdot 8 \\
137 \pm 3 \cdot 6 \\
\\
48 \pm 3 \cdot 0 \\
57 \pm 2 \cdot 6 \\
42 \pm 0 \cdot 4 \\
18 \pm 1 \cdot 2\end{array}$ & $\begin{array}{c}7 \cdot 32 \pm 0 \cdot 00 \\
34 \pm 2 \cdot 1 \\
74 \pm 3 \cdot 1 \dagger \\
91 \pm 8 \cdot 0 \\
138 \pm 2 \cdot 5\end{array}$ & $\begin{array}{c}7 \cdot 32 \pm 0 \cdot 02 \\
29 \pm 2 j 5 \ddagger \\
81 \pm 4 \cdot 0 \\
92 \pm 7 \cdot 4^{\star} \\
138 \pm 3 \cdot 8\end{array}$ \\
\hline
\end{tabular}

Compared with prefeed level: $\star_{P}<0.05 ;+P<0.005 ; \ddagger P<0.001$ (paired t-test).

$\mathrm{PaO}_{2} 15$ minutes from the start of feed followed by recovery after 30 minutes, when $\mathrm{PaCO}_{2}$ had fallen and the respiratory rate had increased. No consistent changes in $p \mathrm{H}$, heart rate, and blood pressure were observed.

In contrast to the two previous studies, no consistent changes were observed in any measurement after feeding ill infants with human milk $(2.5 \mathrm{ml} / \mathrm{kg}$ per feed) (Table IV). A fall of $9 \mathrm{mmHg}$ in $\mathrm{PaO}_{2} 15$ minutes from the start of the feed was recorded in one of the 7 infants but none was observed in the others. This study showed that milk feeds given at a volume of $2.5 \mathrm{ml} / \mathrm{kg}$ per feed were unlikely to cause any cardiorespiratory responses.

The results of feeding distilled water $(5 \mathrm{ml} / \mathrm{kg}$ per feed) to ill infants are shown in Table V. $p \mathrm{H}$ was not affected by feeding. Mean $\mathrm{PaCO}_{2}$ fell from $34 \mathrm{mmHg}$ before feeds to $29 \mathrm{mmHg} 30$ minutes from the start of feeds, but the difference was not significant $(0.05<\mathrm{P}<0.1)$. However, mean $\mathrm{PaO}_{2}$ fell $5 \mathrm{mmHg} 15$ minutes from the start of feeds with recovery to prefeed level by 30 minutes. The difference between the 15-minute and the
TABLE IV

Cardiorespiratory effects of feeding with human breast milk $(2.5 \mathrm{ml} / \mathrm{kg}$ per feed $)$ infants with respiratory distress (mean $\pm S E M$ )

\begin{tabular}{|c|c|c|c|}
\hline & Before feed & $\begin{array}{l}15 \mathrm{~min} \text { from } \\
\text { start of feed }\end{array}$ & $\begin{array}{l}30 \mathrm{~min} \text { from } \\
\text { start of feed }\end{array}$ \\
\hline $\begin{array}{l}\mathrm{pH} \\
\mathrm{PaCO}_{2}(\mathrm{mmHg}) \\
\mathrm{PaO}_{2} \text { (mmHg) } \\
\text { Respiratory rate } \\
\quad \text { (min) } \\
\text { Heart rate } \\
\text { (min) } \\
\text { Blood pressure } \\
\text { (mmHg) } \\
\text { Mean } \\
\text { Systolic } \\
\text { Diastolic } \\
\text { Pulse pressure }\end{array}$ & $\begin{array}{c}7 \cdot 33 \pm 0 \cdot 02 \\
32 \pm 3 \cdot 0 \\
74 \pm 5 \cdot 2 \\
92 \pm 4 \cdot 9 \\
138 \pm 4 \cdot 0 \\
\\
48 \pm 1 \cdot 5 \\
56 \pm 1 \cdot 6 \\
40 \pm 2 \cdot 1 \\
16 \pm 1 \cdot 5\end{array}$ & $\begin{array}{c}7 \cdot 33 \pm 0 \cdot 02 \\
32 \pm 3 \cdot 5 \\
72 \pm 5 \cdot 4 \\
93 \pm 5 \cdot 0 \\
139 \pm 4 \cdot 2 \\
\\
48 \pm 2 \cdot 0 \\
57 \pm 1 \cdot 8 \\
40 \pm 2 \cdot 4 \\
16 \pm 1 \cdot 3\end{array}$ & $\begin{array}{c}7 \cdot 32 \pm 0 \cdot 02 \\
32 \pm 3 \cdot 3 \\
73 \pm 4 \cdot 8 \\
91 \pm 5 \cdot 4 \\
137 \pm 4 \cdot 3\end{array}$ \\
\hline
\end{tabular}

prefeed values is significant $(\mathbf{P}<0 \cdot 05)$. Respiratory rate was increased $(P<0 \cdot 05) 30$ minutes from the start of feeds. No consistent changes in heart rate and blood pressure were observed though the mean fall in $\mathrm{PaO}_{2}$ after feeding with human or cow's milk was $9 \mathrm{mmHg}$ compared with $5 \mathrm{mmHg}$ after feeding with distilled water. The results with these three types of feeding were not statistically different.

It was possible to pass the umbilical venous catheter through the ductus venosus in 7 out of the 14 ill infants, 4 of whom were in group $I$ and 3 in group II. End-expiratory inferior vena caval pressures were reported in this study (Table VI). Mean pressures were not used since the mean is greatly distorted by the negative intrathoracic

\section{TABLE V}

Cardiorespiratory effects of feeding with distilled water (5 $\mathrm{ml} / \mathrm{kg}$ per feed) infants with respiratory distress (mean $\pm S E M)$

\begin{tabular}{|c|c|c|c|}
\hline & Before feed & $\begin{array}{l}15 \mathrm{~min} \text { from } \\
\text { start of feed }\end{array}$ & $\begin{array}{l}30 \mathrm{~min} \text { from } \\
\text { start of feed }\end{array}$ \\
\hline $\begin{array}{l}\mathrm{pH} \\
\mathrm{PaCO}_{2} \text { (mmHg) } \\
\mathrm{PaO}_{2} \text { (mmHg) } \\
\text { Respiratory rate } \\
\text { (min) } \\
\text { Heart rate } \\
\text { (min) } \\
\text { Blood pressure } \\
\text { (mmHg) } \\
\text { Mean } \\
\text { Systolic } \\
\text { Diastolic } \\
\text { Pulse pressure }\end{array}$ & $\begin{array}{c}7 \cdot 31 \pm 0 \cdot 02 \\
34 \pm 1 \cdot 8 \\
81 \pm 4 \cdot 1 \\
87 \pm 5 \cdot 8 \\
137 \pm 3 \cdot 5 \\
\\
51 \pm 2 \cdot 3 \\
60 \pm 2 \cdot 0 \\
43 \pm 2 \cdot 3 \\
17 \pm 0 \cdot 8\end{array}$ & $\begin{array}{c}7 \cdot 32 \pm 0 \cdot 02 \\
35 \pm 1 \cdot 3 \\
76 \pm 5 \cdot 7^{\star} \\
90 \pm 6 \cdot 4 \\
137 \pm 3 \cdot 6\end{array}$ & $\begin{array}{c}7 \cdot 32 \pm 0 \cdot 01 \\
29 \pm 1 \cdot 9 \\
82 \pm 5 \cdot 1 \\
91 \pm 6 \cdot 2^{\star} \\
137 \pm 2 \cdot 5\end{array}$ \\
\hline
\end{tabular}

*Compared with prefeed level: $\mathrm{P}<0.05$ (paired t-test). 
TABLE VI

Central venous and portal sinus pressures before and after feeding (mean $\pm S E M$ )

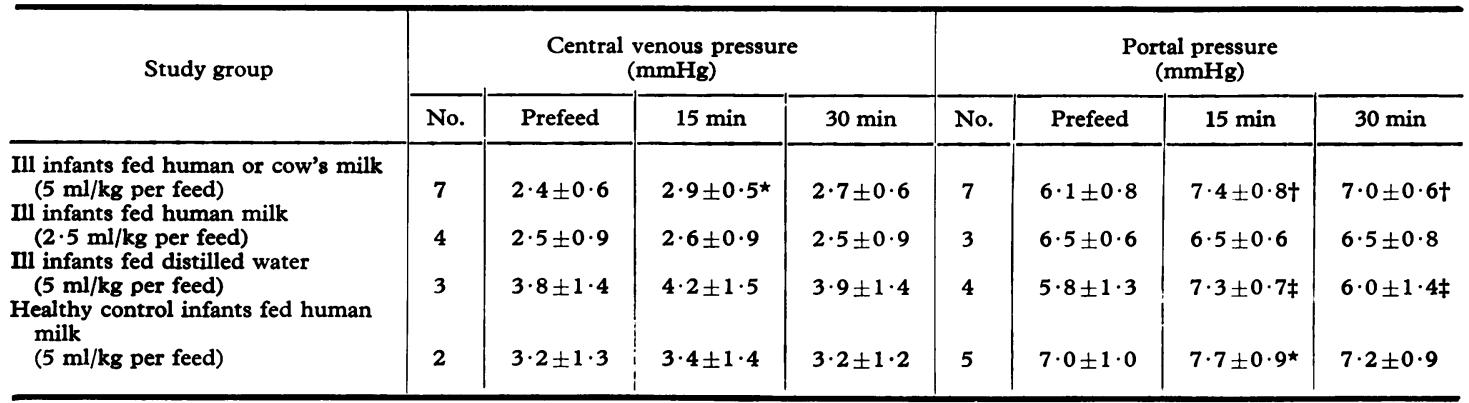

Compared with prefeed levels: ${ }^{\star} \mathrm{P}<0.05 ;+\mathrm{P}<0.02 ; \ddagger 0.05<\mathrm{P}<0.01$ (paired t-test).

pressure with inspiration. Since the observed effects of feeding studies using human or cow's milk at a volume of $5 \mathrm{ml} / \mathrm{kg}$ per feed were similar, these two groups of infants were combined in the analysis of central venous pressure changes with feeding. Thus, for the 7 infants, the pressures before feeds ranged from $0.5-5 \mathrm{mmHg}$ (mean $2.4 \mathrm{mmHg}$ ). The means for the end-expiratory pressures recorded 15 and 30 minutes from the start of feeds were 2.5 and $2.7 \mathrm{mmHg}$ respectively. The difference between the prefeed and the 15minute values is significant $(P<0 \cdot 05)$. Central venous pressure measurements were also available in 4 infants in group I who received human breast milk at a volume of $2.5 \mathrm{ml} / \mathrm{kg}$ per feed. No consistent change in the pressure was observed at this volume of feed. 3 infants in group II who received distilled water feeds at a volume of $5 \mathrm{ml} / \mathrm{kg}$ per feed also had a central venous catheter for study. The means for the end-expiratory pressures recorded prefeed, 15, and 30 minutes from the start of the feed were $3 \cdot 8,4 \cdot 2$, and $3 \cdot 9 \mathrm{mmHg}$, respectively. The small number of observations, however, precluded statistical analysis.

Venous pressure was measured in the portal sinus below the ductus venosus in 4 infants in group I and in 3 infants in group II. The level during expiration was used to indicate the portal sinus pressure in this study. Portal sinus pressures before feeds in the 7 infants ranged from 3.3$8.9 \mathrm{mmHg}$ (mean $6.1 \mathrm{mmHg}$ ). In this combined group receiving either human or cow's milk at a volume of $5 \mathrm{ml} / \mathrm{kg}$ per feed, the means for the end-expiratory pressures recorded at 15 and 30 minutes from the start of the feed were 7.4 and $7.0 \mathrm{mmHg}$, respectively. The difference between these postfeed values and the prefeed portal sinus pressures is significant $(P<0.02)$. No consistent change in portal sinus pressure was observed in the 3 infants in group I who were fed human breast milk at a volume of $2.5 \mathrm{ml} / \mathrm{kg}$ per feed. Portal pressure measurements were available in 4 infants in group II who received distilled water feeds at a volume of $5 \mathrm{ml} / \mathrm{kg}$ per feed. All showed an increase in pressure 15 minutes from the start of feed and in 3 the pressure remained higher than the prefeed value at 30 minutes. Analysis of the four sets of observations, however, showed that the differences did not reach significance $(0.05<\mathrm{P}<$ $0 \cdot 01$ ).

The effects of feeding healthy control infants with human milk ( $5 \mathrm{ml} / \mathrm{kg}$ per feed) are shown in Table VII. Feeding did not affect $p \mathrm{H}, \mathrm{PaCO}_{2}$, and $\mathrm{PaO}_{2}$. No consistent changes were observed with respiratory rate, heart rate, or blood pressure. Portal sinus pressures measured in 5 infants showed an increase 15 minutes from the start of feed

\section{TABLE VII}

Cardiorespiratory effects of feeding with human breast milk (5 ml/kg per feed) healthy infants (mean $\pm S E M)$

\begin{tabular}{|c|c|c|c|}
\hline & Before feed & $\begin{array}{l}15 \mathrm{~min} \text { from } \\
\text { start of feed }\end{array}$ & $\begin{array}{l}30 \mathrm{~min} \text { from } \\
\text { start of feed }\end{array}$ \\
\hline $\begin{array}{l}\mathrm{pH} \\
\mathrm{PaCO}_{2} \text { (mmHg) } \\
\mathrm{PaO}_{2} \text { (mmHg) } \\
\text { Respiratory rate } \\
\text { (min) } \\
\text { Heart rate } \\
\text { Blood pressure } \\
\text { (mmHg) } \\
\text { Mean } \\
\text { Systolic } \\
\text { Diastolic } \\
\text { Pulse pressure }\end{array}$ & $\begin{array}{c}7 \cdot 38 \pm 0 \cdot 03 \\
29 \pm 1 \cdot 3 \\
97 \pm 6 \cdot 5 \\
45 \pm 2 \cdot 5 \\
124 \pm 3 \cdot 1 \\
\\
48 \pm 1 \cdot 5 \\
60 \pm 1 \cdot 9 \\
36 \pm 1 \cdot 5 \\
24 \pm 1 \cdot 2\end{array}$ & $\begin{array}{c}7 \cdot 38 \pm 0 \cdot 02 \\
28 \pm 1 \cdot 8 \\
96 \pm 5 \cdot 8 \\
45 \pm 2 \cdot 5 \\
124 \pm 2 \cdot 7 \\
\\
48 \pm 1 \cdot 9 \\
59 \pm 2 \cdot 5 \\
36 \pm 1 \cdot 5 \\
23 \pm 0 \cdot 8\end{array}$ & $\begin{array}{c}7 \cdot 38 \pm 0 \cdot 02 \\
26 \pm 1 \cdot 5 \\
95 \pm 5 \cdot 4 \\
46 \pm 2 \cdot 7 \\
123 \pm 3 \cdot 1\end{array}$ \\
\hline
\end{tabular}


$P<0 \cdot 05)$. Central venous pressure measurements were available in 2 infants and both showed a slight rise at 15 minutes.

\section{Discussion}

Studies on the metabolic effect of feeding have indicated that the rise in the minimal rate of oxygen consumption after birth can largely be attributed to the intake of milk (Krauss and Auld, 1969; Gentz et al., 1970). A previous study has shown a rise in oxygen consumption within 30 minutes after feeds with a subsequent fall before the next feed (Mestayán et al., 1969). As the infants were undisturbed and fed via indwelling nasogastric tubes as in the present study, this rise in oxygen consumption was thought to be a result of specific dynamic action of food rather than associated with the excitement and work of sucking. The average oxygen consumption after feeding was reported to be $30 \%$ higher than that at the prefeed level. Because infants in this present study were fed more frequently, at intervals of every 2 hours, it is unlikely that a rise and fall in gaseous metabolism between feeds would occur. The pattern of change anticipated was of sequential increases occurring with increasing amounts of food. Experimental evidence for this has been published by Gentz et al. (1970) in studies on newborn piglets, and confirmed by Murdock (1974) in human neonates. They showed cumulative increases in oxygen uptake with age which were attributed to the effect of food. In the present study similar changes of $\mathrm{PaO}_{2}$ were observed with feeding of equal volumes of human or cow's milk as well as distilled water. It is therefore unlikely that specific action of milk feeds was the basis for this disturbance in infants after feeding.

In infants with hyaline membrane disease the direction and magnitude of shunting both through the ductus arteriosus and foramen ovale depends on the relation of pulmonary to systemic vascular resistance and pressure. It is generally accepted that right-to-left shunting at the foramen ovale is common. Though many infants transiently show large right-to-left shunting through the ductus arteriosus, the reverse becomes common after 12 hours of life and frequently combines with the right-to-left shunting through the foramen ovale (Rudolph et al., 1961; Wallgren and Lind, 1967; Stahlman et al., 1972). The significance of the increase in central venous pressure after feeding affecting the magnitude or direction of these shunt patterns remains unclear. An increase in the right-to-left foramen shunt resulting in increased arterial desaturation might be caused by an increase in end-expiratory central venous pressure. However, the observed increases after feeding ranged only from $0 \cdot 2-1.5 \mathrm{mmHg}$.

No adverse effects were observed with feeding human breast milk at a volume of $2.5 \mathrm{ml} / \mathrm{kg}$ per feed. In contrast, distilled water when given in the larger volume of $5 \mathrm{ml} / \mathrm{kg}$ per feed produced similar cardiorespiratory responses to human or cow's milk at this volume. It is therefore likely that the basis of the disturbances was volume displacement by fluids being introduced into the stomach. As the effects were volume-related, they can therefore be avoided by limiting the intake with each feed. A total of $60 \mathrm{ml} / \mathrm{kg}$ is provided in the first day of life by the present feeding regimen. This study suggests that it may be advantageous to feed all sick infants more frequently at intervals of one hour in order to limit the intake of each feed to $2.5 \mathrm{ml} / \mathrm{kg}$ in the first day. The alternative is continuous milk infusion (Landwirth, 1972), but this method of feeding needs further evaluation before being generally applied.

I thank Professor J. P. M. Tizard for his help in the preparation of the manuscript.

\section{REFERENCES}

Gentz, J., Bengtsson, G., Hakkarainen, J., Hellström, R., and Persson, B. (1970). Factors influencing oxygen consumption in the newborn pig with special reference to feeding. Biology of the Neonate, 16, 328.

Krauss, A. N., and Auld, P. A. (1969). Metabolic requirements of low birthweight infants. Fournal of Pediatrics, 75, 952.

Landwirth, J. (1972). Continuous nasogastric infusion versus total intravenous alimentation. Fournal of Pediatrics, 81, 1037.

Mestyán, J., Járai, J., Kekete, M., and Soltész, G. (1969). Specific dynamic action in premature infants kept at and below the neutral temperature. Pediatric Research, 3, 41.

Murdock, A. I. (1974). The first four days of life: serial measurements of intake, output and changes in body weight, gaseous metabolism and total body water in early fed low birthweight infants. Ph.D. thesis, University of London.

Rudolph, A. M., Drorbaugh, J. E., Auld, P. A. M., Rudolph, A. J. Nadas, A. S., Smith, C. A., and Hubbell, J. P. (1961). Studies on the circulation in the neonatal period. The circulation in the respiratory distress syndrome. Pediatrics, 27, 551.

Stahlman, M., Blankenship, W. J., Shepard, F. M., Gray, J., Young, W. C., and Malan, A. F. (1972). Circulatory studies in clinical hyaline membrane disease. Biology of the Neonate, 20, 300.

Wallgren, G., and Lind, J. (1967). Quantitative studies of the human neonatal circulation. Acta Paediatrica Scandinavica, Suppl. 179, 55.

Wilkinson, A., and Yu, V. Y. H. (1974). Immediate effects of feeding on blood-gases and some cardiorespiratory functions in ill newborn infants. Lancet, 1, 1083.

Correspondence to Dr. V. Y. H. Yu, Department of Paediatrics, McMaster University Medical Centre, Hamilton, Ontario, Canada L8S 4J9. 